Sharif University of Technology
Scientia Iranica
Transactions E: Industrial Engineering
http://scientiairanica.sharif.edu

Research Note

\title{
A new fuzzy ELECTRE-based multiple criteria method for personnel selection
}

\author{
M. Jasemi ${ }^{\mathrm{a}, *}$ and E. Ahmadi ${ }^{\mathrm{b}}$ \\ a. Department of Industrial Engineering, K.N. Toosi University of Technology, Tehran, Iran. \\ b. Department of Industrial Engineering, Yazd University, Yazd, Iran. \\ Received 20 October 2015; received in revised form 25 October 2016; accepted 19 December 2016
}

\author{
KEYWORDS \\ Personnel selection; \\ Multiple criteria \\ decision making; \\ Fuzzy ELECTRE; \\ Linguistic variables; \\ Human resources.
}

\begin{abstract}
$\overline{\text { Abstract. In today's competitive environment, qualified human resources are considered }}$ as one of the major keys to the organizations' success. So, an efficient solution to the problem of personnel selection is more necessary than ever. Besides many studies in the literature of the field, this paper presents a novel fuzzy ELECTRE approach which is categorized as a Multiple-Criteria Decision Making (MCDM) technique. In this approach, the weights and ranks are determined by linguistic variables while both quantitative and qualitative criteria are considered simultaneously. At last, the implementation of the model is illustrated and the results are compared with those of TOPSIS.
\end{abstract}

(C) 2018 Sharif University of Technology. All rights reserved.

\section{Introduction}

Personnel selection is the process of choosing certain qualified candidates fit to do the job flawlessly among many others who have applied for a given job in the company. With the increasing competition in the global market, modern organizations face great challenges. The future survival of companies depends mainly on the contribution of their personnel to companies [1].

The personnel's features, such as capability, skill, and other abilities, play a significant role in the successful performance of a typical organization. Therefore, naturally, the organizations always seek powerful and reliable methods to categorize, rank, and select appropriate people to achieve specific goals. Also, the literature is full of studies aimed at contributing to the solutions; refer to Robertson and Smith (2001) for more information [2].

\footnotetext{
*. Corresponding author. Tel.: +1-313-506-4105 E-mail addresses: jasemi@kntu.ac.ir (M. Jasemi); e.ahmadi@stu.yazd.ac.ir (E.Ahmadi)
}

In recent years, regarding the ever-growing advances in information technology, many studies have emphasized application of decision support systems and expert systems as assistance to encounter the challenge [3-5]. Chien and Chen (2008) [6] developed 30 rules as employment strategies on the basis of the decision tree and relational rules. Their framework predicts the workforce behavior by getting their personal features and educational and professional resumes.

Because of the fact that our problem is multidimensional, applying the concept of MCDM is completely logical $[7,8]$, and also since most of the factors and criteria have qualitative nature with vagueness and complexity in their definitions, the fuzzy theory is a good alternative to responding to the challenges $[9,10]$.

Linguistic expressions, such as "satisfied", "reasonable", or/and "dissatisfied", are accepted as preference or judgment of natural expression. These characteristics show the feasibility for a fuzzy set theory to become the preferred structure based on the views of decision-makers. Fuzzy set theory helps to measure the uncertainty of concepts about human subjectivity. Since this evaluation is made up of various evaluators interpreting linguistic variables, this situation has re- 
sulted in uncertainty in the fuzzy environment. MCDM (Multiple Criteria Decision-Making) theory is used in this study to minimize the errors made in the course of decision-making and to strengthen the extent of the process [11].

The fuzzy linguistic models allow for the translation of verbal expressions into numerical ones, thereby dealing quantitatively with imprecision in the expression of the importance of each criterion. There are many studies, such as $[1,2,12-16]$ that combine the concepts of MCDM and fuzzy theory to develop more efficient methods for the problem.

Kelemenis and Askounis (2010) [17] developed a fuzzy MCDM approach on the basis of TOPSIS while, instead of considering positive and negative ideal answers to calculate the distance of each point, the vetoed thresholds are applied. Dursun and Ertugrul Karsak (2010) [14] presented a fuzzy MCDM model with a 2-tuple linguistic representation method besides quantitative and qualitative measures. Güngör et al. (2009) [18] presented a personnel selection system on the basis of Fuzzy Analytical Hierarchy Process (FAHP) in which six methods of fuzzy numbers distance specification are applied to do the comparisons. Lin (2010) [19] combined two methods of Analytical Network Process (ANP) and Fuzzy Data Envelopment Analysis (FDEA) for personnel selection in a Thai electrical company. Kabak et al. (2012) [15] combined Fuzzy ANP and Fuzzy TOPSIS approaches to developing a more accurate personnel selection methodology. For an illustrative example, the proposed model is conducted on a sniper selection process. Afshari et al. (2013) [20] proposed a new linguistic extension of fuzzy measure and fuzzy integral for personnel selection. Sanga et al. (2015) [16] proposed an analytical solution to fuzzy TOPSIS method. Some properties are discussed, and the computation procedure for the proposed analytical solution is given as well compared with the existing TOPSIS method for personnel selection problem. Aliguliyev et al. (2015) [21] proposed an integrated fuzzy MCDM approach to the information personnel evaluation process.

In this paper, an MCDM approach on the basis of fuzzy ELECTRE method is developed for the problem of personnel selection. The ELECTRE (Elimination Et Choix Traduisant la REalité) method for choosing the best action(s) from a given set of actions was introduced in 1965. ELECTRE is a popular approach in MCDM, and it has been widely used in the literature [22]. The main advantage of the ELECTRE method is that the comparison of the alternatives can be achieved even if there is not a clear preference. So, it is more reliable than other methods sensitive to the decision-makers' beliefs. Moreover, it has the ability to handle both quantitative and qualitative judgments.

As the conventional methods for personnel selec- tion are inadequate for dealing with the imprecise or vague nature of linguistic assessment, a new method called the fuzzy technique for ELECTRE (Elimination Et Choix Traduisant la REalité) is proposed. The aim of this study is to compare and contrast TOPSIS and fuzzy ELECTRE methods for personnel selection. The proposed method has been applied to a real case of personnel selection process in one of the greatest and the famous companies in Iran. After determining the criteria that affect the personnel selection decisions, the results of both TOPSIS and fuzzy ELECTRE methods are presented.

The rest of the paper is organized as follows. Section 2 presents the primary points of fuzzy sets and numbers, and Section 3 describes our proposed approach. Section 4 exemplifies the new method and, finally, Section 5 covers the conclusions.

\section{The fuzzy sets in the new approach}

The operations of multiplication and division on triangular fuzzy numbers do not always result in a triangular fuzzy number, but in most of the empirical applications, it is possible to benefit from their estimation [23]. Triangular fuzzy numbers are suitable to quantify the vague information in the field of personnel selection. The main reason for application of this category of fuzzy numbers is their intuitiveness as well as computational efficiency [24].

There are different ways to specify the distance of two triangular fuzzy numbers while, in this study, a method proposed by Cheng (1998) [25] is applied. This method calculates the distance between two triangular fuzzy numbers of $u$ and $w$ as is shown by Eq. (1):

$$
d(u, w)=R(u)-R(w) .
$$

In Eq. (1), $R(u)$ and $R(w)$ are calculated similarly, while, for example, calculation of $R(u)$ is illustrated by Eqs. (2)-(4):

$$
\begin{aligned}
R(u) & =\sqrt{(\bar{x}(u))^{2}+(\bar{y}(u))^{2}}, \\
\bar{x}(u) & =\frac{\int_{a}^{b} x \mu^{L}(x) d x+\int_{b}^{c} x \mu^{R}(x) d x}{\int_{a}^{b} \mu^{L}(x) d x+\int_{b}^{c} \mu^{R}(x) d x}, \\
\bar{y}(u)= & \frac{\int_{0}^{1} y \mu^{-L}(y) d y+\int_{0}^{1} y \mu^{-R}(y) d y}{\int_{0}^{1} \mu^{-L}(y) d y+\int_{0}^{1} \mu^{-R}(y) d y} .
\end{aligned}
$$

To understand the above equations better, a quick review of the concept of fuzzy sets (Zadeh 1965) is 


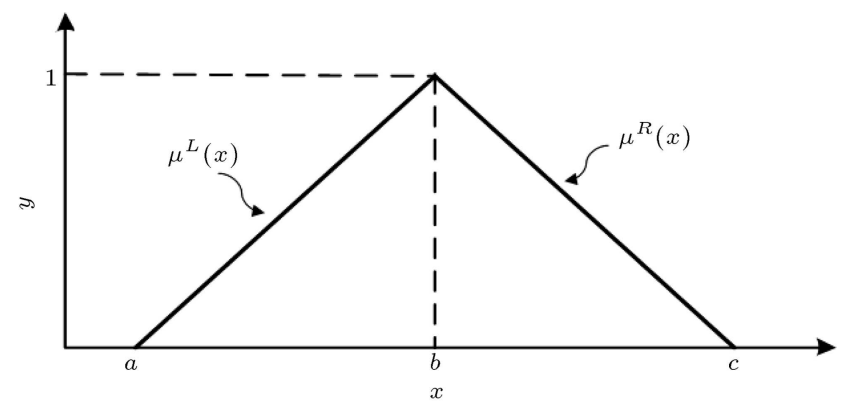

Figure 1. A triangle fuzzy number.

necessary. With the supposition that $X$ is a reference set, $\widetilde{A}$ is a fuzzy subset of $X$ if $\forall x \in X$ and $\mu_{\widetilde{A}}(x) \in$ $[0,1]$ which is known as membership degree of $x$ in $\widetilde{A}$, and $\mu_{\widetilde{A}}$ is membership function of $\widetilde{A}$. $\widetilde{A}$ is normal and convex fuzzy subset. The normality means that $\mu_{\widetilde{A}}(x)=1$ only for one $x \in \widetilde{A}$, while Relation (5) illustrates the concept of convexity:

$$
\begin{aligned}
& \forall x_{1}, x_{2} \in X \text { and } \forall \alpha \in[0,1] \\
& \Rightarrow \mu_{\widetilde{A}}\left(\alpha x_{1}+(1-\alpha) x_{2}\right) \geq \min \left(\mu_{\widetilde{A}}\left(x_{1}\right), \mu_{\widetilde{A}}\left(x_{1}\right)\right) .
\end{aligned}
$$

A triangular fuzzy number, such as $\widetilde{A}$, can be defined as a triple of $(a, b, c)$ as is shown in Figure 1, while $\mu^{-L}(y)$ and $\mu^{-R}(y)$ of Eq. (4) are the inverse cases of $\mu^{L}(x)$ and $\mu^{R}(x)$, respectively. In this regard, Relation (6) presents the membership function:

$$
\mu_{\tilde{A}}(x)=\left\{\begin{array}{lc}
0 & x<a \\
\frac{x-a}{b-a} & a \leq x \leq b \\
\frac{c-x}{c-b} & b \leq x \leq c \\
0 & x>c
\end{array}\right.
$$

\section{The proposed approach}

MCDM problems can be categorized into two categories of Multiple-Attribute Decision Making (MADM) and Multiple-Objective Decision Making (MODM): the former is concerned with selecting a limited number of alternatives on the basis of some criteria; the latter deals with the optimal alternative according to some semi-inconsistent objectives. There are many different methods that have been developed to solve MADM problems among which AHP and TOPSIS are the most considerable ranking methods, and ELECTRE and PROMETHE are the most important outranking methods.

ELECTRE was developed by Roy (1968) [26] for the first time; then, different modifications have been made to it characterized as ELECTRE I, II, III, IV, and TRI where all of them have same basic features, but deal with different problems. This method can be considered as a non-compensatory one, i.e. an alternative low score under a criterion cannot be compensated by high scores on other criteria [27]. Another important feature of the method is consideration of incomparability. For instance, two alternatives of $x$ and $y$ are not in any competition for the superiority of one over another.

In ELECTRE, priority is expressed by the outranking relationship of S. For example, the relationship of $x S y$ means that "at least $\mathrm{x}$ is as good as $\mathrm{y}$ ".

Therefore, the four following states can be conceived:

- xSy is established and ySx is not established; then, $\mathrm{x}$ is superior to $\mathrm{y}(\mathrm{xPy})$;

- $\mathrm{xSy}$ is not established and $\mathrm{ySx}$ is established; then, $\mathrm{y}$ is superior to $\mathrm{x}(\mathrm{yPx})$;

- $\mathrm{xSy}$ and $\mathrm{ySx}$ are established; then, $\mathrm{x}$ and $\mathrm{y}$ are indifferent to each other;

- xSy and ySx are not established; then, $\mathrm{x}$ and $\mathrm{y}$ are not comparable.

ELECTRE has different applications in many fields, especially engineering [28]. Montazer et al. (2009) [29] used ELECTRE III for the problem of supplier selection. Afshari et al. (2010) [20] surveyed the personnel selection problem by ELECTRE under the condition of crisp weights and ranks. The proposed approach is illustrated in the following eleven steps.

\subsection{Organization of decision-maker team}

Since personnel selection is a critical process in organizations, relying on group decisions is wiser than individual decisions [17]. So, in the first step of our approach, a committee consisting of $K$ people (including top managers and experts of different departments) is organized as the Decision-Maker (DM) team.

\subsection{Criteria selection}

In each organization, two groups of criteria, including individual and non-individual groups, are usually considered to evaluate the human resources. These criteria should be defined in the way that cover the DMs issues as well as the job issues. This should be done regarding the environment in which the company works and the position for which the human resource is employed.

\subsection{Selection of linguistic sets for weighting, ranking, and specifying the candidates}

A linguistic variable is a variable whose values are presented in linguistic terms, words, or sentences [30]. For example, communication skill is a linguistic variable if its values are linguistically weak, average, and good. Any value of such variables can be shown by a fuzzy number, while, in our approach, the triangular fuzzy numbers are applied. Linguistic sets can have different scales. In this study, regarding the literature, the fivepoint scale is suggested for weighing the criteria and ranking the alternatives. 


\subsection{Weighing the criteria and ranking the alternatives (applicants) by DMs}

Each DM ranks each person on the basis of the linguistic variables of the previous step. It should be noted that only the qualitative evaluation of the alternatives is done by DMs with linguistic variables; moreover, for the quantitative criteria (like employment exam), the person's score is considered as her/his rank under the associated criteria.

\subsection{Fuzzy decision-making matrix}

There is an equivalent fuzzy number for each linguistic variable; thus, by Eq. (7), the specified linguistic weights and ranks are translated into their fuzzy equivalents on the basis of which the fuzzy decision-making matrix of $\widetilde{D}$ is achieved as is shown by Relation (8):

$$
\begin{aligned}
\widetilde{r}_{i j} & =\frac{1}{K}\left[\widetilde{r}_{i j 1} \oplus \widetilde{r}_{i j 2} \oplus \ldots \oplus \widetilde{r}_{i j k}\right], \\
i & =1, \ldots, m, \quad j=1, \ldots, n, \\
\widetilde{D} & =\left[\widetilde{r}_{i j}\right]_{m n}, \quad i=1, \ldots, m, \quad j=1, \ldots, n,
\end{aligned}
$$

where $\widetilde{r}_{i j k}$ is the rank that the $k$ th $\mathrm{DM}$ gives to the $i$ th person on the basis of the $j$ th criterion; $m, n$, and $K$ are the number of candidates, criteria, and DMs, respectively. The criteria weights vector (Relation (9)) is obtained by Relation (10):

$$
\begin{aligned}
\widetilde{W} & =\left[\widetilde{w}_{1}, \ldots, \widetilde{w}_{n}\right], \\
\widetilde{w}_{j} & =\frac{1}{K}\left[\widetilde{w}_{j 1} \oplus \ldots \oplus \widetilde{w}_{j K}\right],
\end{aligned}
$$

where $\widetilde{w}_{j k}$ is the weight that the $k$ th DM gives to the $j$ th criterion.

\subsection{Normalization of the fuzzy decision-making matrix}

In this step, the fuzzy decision-making matrix is normalized by application of Relations (11) and (12). $\tilde{r}_{i j}=\left(a_{i j}, b_{i j}, c_{i j}\right)$ is the $i$ th person rank on the basis of the $j$ th criterion. $B$ is the set of criteria whose greater amounts are more desirable, and $C$ is the set of criteria whose smaller amounts are more desirable:

$$
\begin{aligned}
& \left\{\begin{array}{l}
\tilde{\eta}_{i j}=\left(\frac{a_{i j}}{c_{j}^{+}}, \frac{b_{i j}}{c_{j}^{+}}, \frac{c_{i j}}{c_{j}^{+}}\right) ; j \in B \\
c_{j}^{+}=\operatorname{Max}_{i} c_{i j} ; j \in B
\end{array}\right. \\
& \left\{\begin{array}{l}
\tilde{\eta}_{i j}=\left(\frac{a_{i j}}{c_{j}^{+}}, \frac{b_{i j}}{c_{j}^{+}}, \frac{c_{i j}}{c_{j}^{+}}\right) ; j \in C \\
c_{j}^{+}=\operatorname{Max}_{i} c_{i j} ; j \in C
\end{array}\right.
\end{aligned}
$$

where $\widetilde{\eta}_{i j}$ is the normalized amount of $\widetilde{r}_{i j}$. At last, the normalized fuzzy decision-making matrix is obtained as in Relation (13):

$$
\widetilde{N}_{D}=\left[\widetilde{\eta}_{i j}\right]_{m n} ; \quad i=1, \ldots, m, \quad j=1, \ldots, n .
$$

\subsection{Making the weighted normalized fuzzy decision matrix}

In this step, the criteria weights are applied to the decision matrix. In this regard, each row of $\widetilde{N}_{D}$ is multiplied by the criteria weights vector, $\widetilde{W}$, element by element, as shown by Relation (14):

$$
\begin{aligned}
& \widetilde{v}_{i j}=\widetilde{\eta}_{i j} \otimes \widetilde{w}_{j} ; i=1, \ldots, m ; j=1, \ldots, n \\
& \text { (while } \widetilde{V}=\left[\widetilde{v}_{i j}\right]_{m n} \text { ). }
\end{aligned}
$$

\subsection{Specifying the concordanced and non-concordanced sets}

In this step, all the alternatives are evaluated according to all the criteria, couple by couple, and then the sets are organized. The concordance set of $S_{k l}$ (as is illustrated by Relation (15)) covers all the criteria indices where alternative $A_{k}$ is superior to $A_{l}$ :

$$
S_{k l}=\left\{j \mid \widetilde{v}_{k j} \geq \widetilde{v}_{l j}\right\}
$$

The non-concordance set of $D_{k l}$ (as is illustrated by Relation (16)) covers all the criteria indices where alternative $A_{l}$ is superior to $A_{k}$ :

$$
D_{k l}=\left\{j \mid \widetilde{v}_{k j} \leq \widetilde{v}_{l j}\right\} .
$$

On the basis of the method of Cheng (1998) [25] for distance specification, $\widetilde{v}_{k j} \geq \widetilde{v}_{l j}$ is established if and only if $d\left(\widetilde{v}_{k j}, \widetilde{v}_{l j}\right) \geq 0$, and if $d\left(\widetilde{v}_{k j}, \widetilde{v}_{l j}\right) \leq 0$, then $\widetilde{v}_{k j} \leq$ $\widetilde{v}_{l j}$

\subsection{Calculation of the concordance and non-concordance matrices}

Concordance matrix of $\widetilde{I}$ is an $m \times m$ matrix with an empty main diameter, while its other elements are obtained by adding the criteria weights of the concordance sets of $k$ and $l$ as shown by Relation (17):

$$
\widetilde{I}_{k l}=\sum_{j \in S_{k l}} \widetilde{w}_{j} ; \widetilde{I}=\left[\widetilde{I}_{k l}\right]_{m m},
$$

where $\widetilde{I}_{k l}$ denotes the relative importance of $A_{k}$ over $A_{l}$.

Non-concordance matrix of $N I$ is an $m \times n$ matrix with an empty main diameter, while its other elements are obtained by Relation (18) to come to the final matrix, as shown by Relation (19):

$$
\begin{aligned}
& N I_{k l}=\frac{\operatorname{Max}_{j \in D_{k l}}\left|\widetilde{v}_{k j}-\widetilde{v}_{l j}\right|}{\operatorname{Max}_{j \in J}\left|\widetilde{v}_{k j}-\widetilde{v}_{l j}\right|}=\frac{\operatorname{Max}_{j \in D_{k l}}\left|d\left(\widetilde{v}_{k j}-\widetilde{v}_{l j}\right)\right|}{\operatorname{Max}_{j \in J}\left|d\left(\widetilde{v}_{k j}-\widetilde{v}_{l j}\right)\right|}, \\
& N I=\left[N I_{k l}\right]_{m m},
\end{aligned}
$$

where $J$ covers the indices of all the criteria. 


\subsection{Specifying the effective concordance and non-concordance matrices}

To specify the effective concordance matrix $(H)$, first of all, the threshold limit must be determined. If an element of the concordance matrix of $\widetilde{I}$ is greater than or equal to the threshold limit, its equivalent in the effective concordance matrix will be one, otherwise zero. The threshold limit can be calculated as is shown by Relation (20):

$$
\widetilde{\bar{I}}=\frac{1}{m(m-1)} \sum_{k=1}^{m} \sum_{l=1}^{m} \widetilde{I}_{k l} .
$$

It is obvious that $\widetilde{\bar{I}}=\left(\widetilde{\bar{I}^{a}}, \widetilde{\bar{I}^{b}}, \widetilde{\bar{I}}^{c}\right)$ where, for example, $\widetilde{\bar{I}^{a}}$ is calculated by Eq. (21):

$$
\widetilde{\bar{I}^{a}}=\frac{1}{m(m-1)} \sum_{k=1}^{m} \sum_{l=1}^{m} \widetilde{I}_{k l}^{a} .
$$

This method used to calculate the threshold limit is not the only one available, and application of any of these methods depends on the user's decision.

After calculating $\widetilde{\bar{I}}$, the effective concordance matrix (Relation (22)) is accessible by Relation (23):

$$
\begin{aligned}
& H=\left[H_{k l}\right]_{m m} ; \quad k, l=1,2, \ldots, m, \\
& H_{k l}= \begin{cases}1 & \widetilde{I}_{k l} \geq \widetilde{\bar{I}} \\
0 & \widetilde{I}_{k l}<\widetilde{\bar{I}}\end{cases}
\end{aligned}
$$

To specify the effective non-concordance matrix $(G)$, such as the concordance version, first of all, the threshold limit of $\bar{N} \bar{I}$ is calculated by Relation (24):

$$
\bar{N} \bar{I}=\frac{1}{m(m-1)} \sum_{k=1}^{m} \sum_{1}^{m} N I_{k l} .
$$

Then, the effective non-concordance matrix can be achieved by Relation (25):

$$
G_{k l}= \begin{cases}0 & N I_{k l} \geq \bar{N} \bar{I} \\ 1 & N I_{k l}<\bar{N} \bar{I}\end{cases}
$$

\subsection{Specifying the total matrix}

The total matrix $(F)$ indicates the relative priorities of the alternatives. For example, $F_{k l}=1$ means that $A_{k}$ is superior to $A_{l}$. The matrix can be achieved according to Relation (26):

$$
\begin{aligned}
& F_{k l}=H_{k l} \times G_{k l} ; k, l=1,2, \ldots, m \\
& \left(\text { while } F=\left[F_{k l}\right]_{m m}\right) .
\end{aligned}
$$

After calculation of $F$, a directed graph is usually drawn accordingly. The nodes represent the alternatives and the edges or arcs are on the basis of the

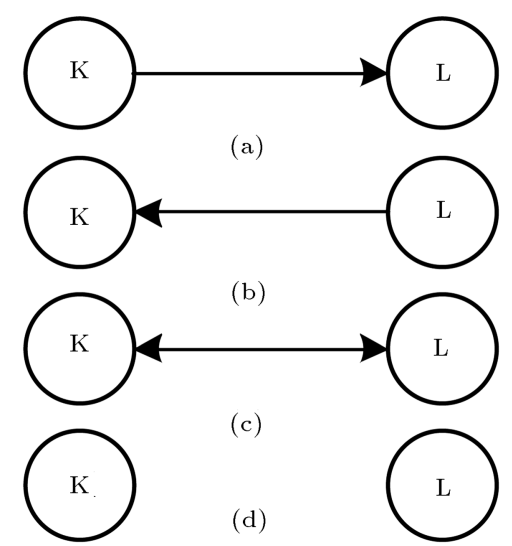

Figure 2. Different possible states between two nodes.

matrix numbers. For example, if $F_{\mathrm{KL}}=1$, an arc is drawn from nodes $K$ to $L$. Figure 2 shows different possible states between two nodes. The first state (Figure 2(a)) indicates the relation (K P L), the second state (Figure $2(\mathrm{~b})$ ) indicates the relation ( $\mathrm{L} \mathrm{P} \mathrm{K}$ ), the third state (Figure 2(c)) indicates the relation (K I L), and the last state (Figure $2(\mathrm{~d})$ ) indicates the relation (K R L).

\section{A numerical example}

A famous pipe manufacturing plant in Iran needs to employ an industrial engineer. Five candidates of $A_{1}, A_{2}, A_{3}, A_{4}$, and $A_{5}$ remain after a primary screening. A four-member committee $\left(\mathrm{DM}_{1}, \mathrm{DM}_{2}\right.$, $\mathrm{DM}_{3}$, and $\mathrm{DM}_{4}$ ) is organized to do the interview and select the most suitable candidate. The eight considered criteria are as follows: emotional stability $\left(C_{1}\right)$, leadership $\left(C_{2}\right)$, self-confidence $\left(C_{3}\right)$, proficiency in oral communication $\left(C_{4}\right)$, personality $\left(C_{5}\right)$, previous experiences $\left(C_{6}\right)$, competency and general capability $\left(C_{7}\right)$, and perception and understanding $\left(C_{8}\right)$. The first six criteria are categorized as individual criteria, and the last two criteria are categorized as non-individual ones, i.e., work-wise. The solving procedure on the basis of the algorithm steps is as follows:

- Steps 1 and 2: These steps are related to the decision-making team and specification of the criteria that have already been done;

- Step 3: The linguistic sets of $W$ and $A$ denote weighting the criteria and ranking the alternatives. Their membership functions as triangular fuzzy numbers are shown in Figures 3 and 4;

- Step 4: Every DM determines the weights of criteria and the ranks of alternatives by the linguistic variables of $W$ and $A$, respectively, while the results can be seen in Tables 1 and 2. It is to be noted that the last two criteria of $C_{7}$ and $C_{8}$ are quantitative, and to rank the alternatives on the basis of these criteria, the DMs opinions are not needed and the 


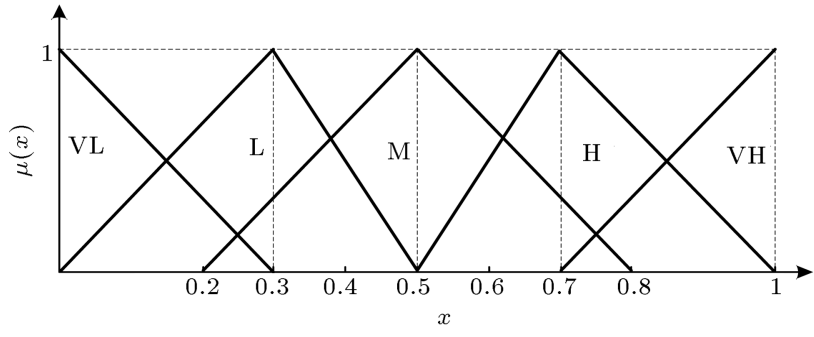

Figure 3. The membership function of the linguistic variables of $W$ for weighting the criteria.

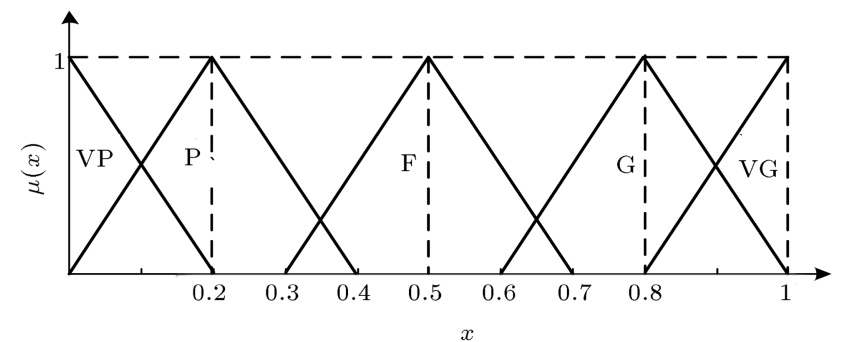

Figure 4. The membership function of the linguistic variables of $A$ for ranking the alternatives.

obtained grades of each person for these measures are considered as her/his rank or score, as shown in Table 3;

- Step 5: Table 4 shows the fuzzy values of the alternatives rankings that are presented in Table 2 linguistically. After applying Relations (7) and (8), the decision-making matrix as shown in Table 5 is obtained. It should be noted that the definite values related to criteria of $C_{7}$ and $C_{8}$ are written as triangular fuzzy numbers. For instance, 95 is written as $(95,95,95)$. Besides, by applying Eq. (10), the criteria weights vector is also organized;

- Step 6: Regarding the fact that all the criteria are positive attributes and greater, they are more desirable, and the decision-making matrix is normalized by Relation (11) as is shown in Table 6;

- Step 7: Table 7 indicates the weighted normalized decision matrix calculated by Relation (14);

- Step 8: Applying the Cheng method [25] and Relations (15) and (16), the concordance and nonconcordance sets are obtained as shown in Tables 8 and 9 ;

- Step 9: The concordance and non-concordance matrices are obtained by Relations (17) to (19), while the results are shown in Tables 10 and 11, respectively;

- Step 10: The effective matrices are obtained; therefore, first, the threshold limit should be calculated by Relations (20) and (24) as follows:

$$
\widetilde{\bar{I}}=\left(\widetilde{\bar{I}^{a}}, \widetilde{\bar{I}^{b}}, \widetilde{\bar{I}^{c}}\right)=(2.29,3.35,4.05) ; \quad \bar{N} \bar{I}=0.73 .
$$

Table 1. The criteria weights by the DMs.

\begin{tabular}{ccccc}
\hline & \multicolumn{4}{c}{ DMs } \\
\cline { 2 - 5 } Criteria & $\mathbf{1}$ & $\mathbf{2}$ & $\mathbf{3}$ & $\mathbf{4}$ \\
\hline$C_{1}$ & $\mathrm{M}$ & $\mathrm{H}$ & $\mathrm{H}$ & $\mathrm{H}$ \\
$C_{2}$ & $\mathrm{VH}$ & $\mathrm{VH}$ & $\mathrm{M}$ & $\mathrm{VH}$ \\
$C_{3}$ & $\mathrm{H}$ & $\mathrm{M}$ & $\mathrm{H}$ & $\mathrm{VH}$ \\
$C_{4}$ & $\mathrm{H}$ & $\mathrm{VH}$ & $\mathrm{VH}$ & $\mathrm{VH}$ \\
$C_{5}$ & $\mathrm{H}$ & $\mathrm{H}$ & $\mathrm{H}$ & $\mathrm{VH}$ \\
$C_{6}$ & $\mathrm{H}$ & $\mathrm{VH}$ & $\mathrm{H}$ & $\mathrm{VH}$ \\
$C_{7}$ & $\mathrm{H}$ & $\mathrm{H}$ & $\mathrm{M}$ & $\mathrm{H}$ \\
$C_{8}$ & $\mathrm{VH}$ & $\mathrm{VH}$ & $\mathrm{VH}$ & $\mathrm{H}$ \\
\hline
\end{tabular}

Table 2. The alternatives ranks by the DMs.

\begin{tabular}{|c|c|c|c|c|c|}
\hline \multirow[b]{2}{*}{ Criteria } & \multirow[b]{2}{*}{ Alternatives } & \multicolumn{4}{|c|}{ DMs } \\
\hline & & 1 & 2 & 3 & 4 \\
\hline \multirow{5}{*}{$C_{1}$} & $A_{1}$ & $\mathrm{~F}$ & $\mathrm{P}$ & $\mathrm{F}$ & $\mathrm{F}$ \\
\hline & $A_{2}$ & $\mathrm{~F}$ & $\mathrm{~F}$ & $\mathrm{~F}$ & $\mathrm{~F}$ \\
\hline & $A_{3}$ & $\mathrm{~F}$ & $\mathrm{~F}$ & $\mathrm{~F}$ & $\mathrm{G}$ \\
\hline & $A_{4}$ & G & G & G & $\mathrm{VG}$ \\
\hline & $A_{5}$ & $\mathrm{~F}$ & VG & $\mathrm{F}$ & $\mathrm{F}$ \\
\hline \multirow{5}{*}{$C_{2}$} & $A_{1}$ & $\mathrm{~F}$ & $\mathrm{~F}$ & $\mathrm{~F}$ & $\mathrm{P}$ \\
\hline & $A_{2}$ & VP & $\mathrm{F}$ & $\mathrm{F}$ & $\mathrm{F}$ \\
\hline & $A_{3}$ & $\mathrm{G}$ & VG & G & G \\
\hline & $A_{4}$ & G & $\mathrm{G}$ & G & G \\
\hline & $A_{5}$ & G & VG & G & G \\
\hline \multirow{5}{*}{$C_{3}$} & $A_{1}$ & $\mathrm{VG}$ & VG & G & G \\
\hline & $A_{2}$ & $\mathrm{~F}$ & VG & VG & $\mathrm{G}$ \\
\hline & $A_{3}$ & G & VG & $\mathrm{G}$ & G \\
\hline & $A_{4}$ & $\mathrm{~F}$ & G & $\mathrm{F}$ & G \\
\hline & $A_{5}$ & G & $\mathrm{VG}$ & VG & G \\
\hline \multirow{5}{*}{$C_{4}$} & $A_{1}$ & VP & VG & G & VP \\
\hline & $A_{2}$ & G & $\mathrm{G}$ & G & G \\
\hline & $A_{3}$ & $\mathrm{~F}$ & $\mathrm{~F}$ & $\mathrm{~F}$ & G \\
\hline & $A_{4}$ & G & $\mathrm{F}$ & G & $\mathrm{F}$ \\
\hline & $A_{5}$ & VG & $\mathrm{P}$ & G & $\mathrm{F}$ \\
\hline \multirow{5}{*}{$C_{5}$} & $A_{1}$ & $\mathrm{~F}$ & G & $\mathrm{F}$ & $\mathrm{F}$ \\
\hline & $A_{2}$ & $\mathrm{~F}$ & G & F & $\mathrm{F}$ \\
\hline & $A_{3}$ & $\mathrm{~F}$ & $\mathrm{~F}$ & F & $\mathrm{G}$ \\
\hline & $A_{4}$ & $\mathrm{VG}$ & $\mathrm{VG}$ & G & $\mathrm{VG}$ \\
\hline & $A_{5}$ & $\mathrm{G}$ & $\mathrm{G}$ & $\mathrm{F}$ & $\mathrm{F}$ \\
\hline \multirow{5}{*}{$C_{6}$} & $A_{1}$ & $\mathrm{P}$ & $\mathrm{VG}$ & $\mathrm{G}$ & $\mathrm{F}$ \\
\hline & $A_{2}$ & VP & $\mathrm{VG}$ & $\mathrm{F}$ & VP \\
\hline & $A_{3}$ & $\mathrm{G}$ & $\mathrm{G}$ & VG & $\mathrm{G}$ \\
\hline & $A_{4}$ & $\mathrm{VG}$ & $\mathrm{VG}$ & VG & $\mathrm{VG}$ \\
\hline & $A_{5}$ & $\mathrm{G}$ & $\mathrm{G}$ & $\mathrm{G}$ & $\mathrm{G}$ \\
\hline
\end{tabular}


Now, regarding Relations (23) and (25), the effective concordance and non-concordance matrices are achieved and shown in Tables 12 and 13, respectively;

Table 3. The alternatives ranks for the non-individual criteria.

\begin{tabular}{cccccc} 
& \multicolumn{5}{c}{ Alternatives } \\
\cline { 2 - 6 } Criteria & $\boldsymbol{A}_{\mathbf{1}}$ & $\boldsymbol{A}_{\mathbf{2}}$ & $\boldsymbol{A}_{\mathbf{3}}$ & $\boldsymbol{A}_{\mathbf{4}}$ & $\boldsymbol{A}_{\mathbf{5}}$ \\
\hline$C_{7}$ & 53 & 43 & 75 & 85 & 83 \\
$C_{\mathbf{8}}$ & 39 & 38 & 79 & 86 & 86 \\
\hline
\end{tabular}

- Step 11: The total matrix of $F$ is calculated by multiplying the two effective concordance and nonconcordance matrices element by element according to Relation (26), as shown in Table 14.

The corresponding graph of matrix $F$ is shown in Figure 5. As it is obvious in the graph, $A_{4}$ and $A_{5}$ are superior over all the other alternatives, and there is no clear intuition about their superiority over each other. $A_{3}$ has superiority over the others. $A_{1}$ and $A_{2}$ are similar and inferior to the other alternatives. Alternatives $A_{1}$ and $A_{3}$ have relation $R$, i.e. they are incomparable and there is no clear intuition about their

Table 4. The fuzzy equivalents of the alternatives rankings.

\begin{tabular}{|c|c|c|c|c|c|}
\hline \multirow[b]{2}{*}{ Criteria } & \multirow[b]{2}{*}{ Alternatives } & \multicolumn{4}{|c|}{ DMs } \\
\hline & & 1 & 2 & 3 & 4 \\
\hline \multirow{5}{*}{$C_{1}$} & $A_{1}$ & $(0.3,0.5,0.7)$ & $(0,0.2,0.4)$ & $(0.3,0.5,0.7)$ & $(0.3,0.5,0.7)$ \\
\hline & $A_{2}$ & $(0.3,0.5,0.7)$ & $(0.3,0.5,0.7)$ & $(0.3,0.5,0.7)$ & $(0.3,0.5,0.7)$ \\
\hline & $A_{3}$ & $(0.3,0.5,0.7)$ & $(0.3,0.5,0.7)$ & $(0.3,0.5,0.7)$ & $(0.6,0.8,1)$ \\
\hline & $A_{4}$ & $(0.6,0.8,1)$ & $(0.6,0.8,1)$ & $(0.6,0.8,1)$ & $(0.8,1,1)$ \\
\hline & $A_{5}$ & $(0.3,0.5,0.7)$ & $(0.8,1,1)$ & $(0.3,0.5,0.7)$ & $(0.3,0.5,0.7)$ \\
\hline \multirow{5}{*}{$C_{2}$} & $A_{1}$ & $(0.3,0.5,0.7)$ & $(0.3,0.5,0.7)$ & $(0.3,0.5,0.7)$ & $(0,0.2,0.4)$ \\
\hline & $A_{2}$ & $(0,0,0.2)$ & $(0.3,0.5,0.7)$ & $(0.3,0.5,0.7)$ & $(0.3,0.5,0.7)$ \\
\hline & $A_{3}$ & $(0.6,0.8,1)$ & $(0.8,1,1)$ & $(0.6,0.8,1)$ & $(0.6,0.8,1)$ \\
\hline & $A_{4}$ & $(0.6,0.8,1)$ & $(0.6,0.8,1)$ & $(0.6,0.8,1)$ & $(0.6,0.8,1)$ \\
\hline & $A_{5}$ & $(0.6,0.8,1)$ & $(0.8,1,1)$ & $(0.6,0.8,1)$ & $(0.6,0.8,1)$ \\
\hline \multirow{5}{*}{$C_{3}$} & $A_{1}$ & $(0.8,1,1)$ & $(0.8,1,1)$ & $(0.6,0.8,1)$ & $(0.6,0.8,1)$ \\
\hline & $A_{2}$ & $(0.3,0.5,0.7)$ & $(0.8,1,1)$ & $(0.8,1,1)$ & $(0.6,0.8,1)$ \\
\hline & $A_{3}$ & $(0.6,0.8,1)$ & $(0.8,1,1)$ & $(0.6,0.8,1)$ & $(0.6,0.8,1)$ \\
\hline & $A_{4}$ & $(0.3,0.5,0.7)$ & $(0.6,0.8,1)$ & $(0.3,0.5,0.7)$ & $(0.6,0.8,1)$ \\
\hline & $A_{5}$ & $(0.6,0.8,1)$ & $(0.8,1,1)$ & $(0.8,1,1)$ & $(0.6,0.8,1)$ \\
\hline \multirow{5}{*}{$C_{4}$} & $A_{1}$ & $(0,0,0.2)$ & $(0.8,1,1)$ & $(0.6,0.8,1)$ & $(0,0,0.2)$ \\
\hline & $A_{2}$ & $(0.6,0.8,1)$ & $(0.6,0.8,1)$ & $(0.6,0.8,1)$ & $(0.6,0.8,1)$ \\
\hline & $A_{3}$ & $(0.3,0.5,0.7)$ & $(0.3,0.5,0.7)$ & $(0.3,0.5,0.7)$ & $(0.6,0.8,1)$ \\
\hline & $A_{4}$ & $(0.6,0.8,1)$ & $(0.3,0.5,0.7)$ & $(0.6,0.8,1)$ & $(0.3,0.5,0.7)$ \\
\hline & $A_{5}$ & $(0.8,1,1)$ & $(0,0.2,0.4)$ & $(0.6,0.8,1)$ & $(0.3,0.5,0.7)$ \\
\hline \multirow{5}{*}{$C_{5}$} & $A_{1}$ & $(0.3,0.5,0.7)$ & $(0.6,0.8,1)$ & $(0.3,0.5,0.7)$ & $(0.3,0.5,0.7)$ \\
\hline & $A_{2}$ & $(0.3,0.5,0.7)$ & $(0.6,0.8,1)$ & $(0.3,0.5,0.7)$ & $(0.3,0.5,0.7)$ \\
\hline & $A_{3}$ & $(0.3,0.5,0.7)$ & $(0.3,0.5,0.7)$ & $(0.3,0.5,0.7)$ & $(0.6,0.8,1)$ \\
\hline & $A_{4}$ & $(0.8,1,1)$ & $(0.8,1,1)$ & $(0.6,0.8,1)$ & $(0.8,1,1)$ \\
\hline & $A_{5}$ & $(0.6,0.8,1)$ & $(0.6,0.8,1)$ & $(0.3,0.5,0.7)$ & $(0.3,0.5,0.7)$ \\
\hline \multirow{5}{*}{$C_{6}$} & $A_{1}$ & $(0,0.2,0.4)$ & $(0.8,1,1)$ & $(0.6,0.8,1)$ & $(0.3,0.5,0.7)$ \\
\hline & $A_{2}$ & $(0.8,1,1)$ & $(0.8,1,1)$ & $(0.3,0.5,0.7)$ & $(0,0,0.2)$ \\
\hline & $A_{3}$ & $(0.6,0.8,1)$ & $(0.6,0.8,1)$ & $(0.8,1,1)$ & $(0.6,0.8,1)$ \\
\hline & $A_{4}$ & $(0.8,1,1)$ & $(0.8,1,1)$ & $(0.8,1,1)$ & $(0.8,1,1)$ \\
\hline & $A_{5}$ & $(0.6,0.8,1)$ & $(0.6,0.8,1)$ & $(0.6,0.8,1)$ & $(0.6,0.8,1)$ \\
\hline
\end{tabular}


Table 5. The fuzzy decision-making matrix of $D$.

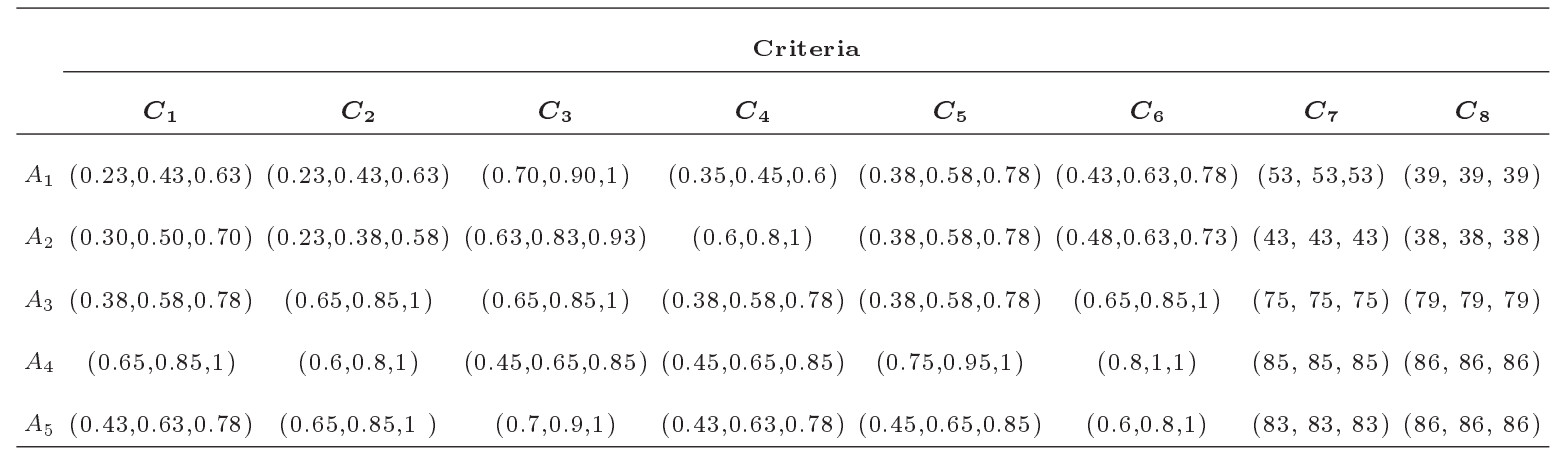

Table 6. The normalized fuzzy decision-making matrix.

\begin{tabular}{|c|c|c|c|c|c|c|c|c|}
\hline \multicolumn{9}{|c|}{ Criteria } \\
\hline & $C_{1}$ & $C_{2}$ & $C_{3}$ & $C_{4}$ & $C_{5}$ & $C_{6}$ & $C_{7}$ & $C_{8}$ \\
\hline$A_{1}$ & $(0.23,0.43,0.63)$ & $(0.23,0.43,0.63)$ & $(0.70,0.90,1)$ & $(0.35,0.45,0.6)$ & $(0.38,0.58,0.78)$ & $(0.43,0.63,0.78)$ & $(0.62,0.62,0.62)$ & $(0.45,0.45,0.45)$ \\
\hline$A_{2}$ & $(0.30,0.50,0.70)$ & $(0.23,0.38,0.58)$ & $(0.63,0.83,0.93)$ & $(0.6,0.8,1)$ & $(0.38,0.58,0.78)$ & $(0.48,0.63,0.73)$ & $(0.51,0.51,0.51)$ & $(0.97,0.97,0.97)$ \\
\hline$A_{3}$ & $(0.38,0.58,0.78)$ & $(0.65,0.85,1)$ & $(0.65,0.85,1)$ & $(0.38,0.58,0.78)$ & $(0.38,0.58,0.78)$ & $(0.65,0.85,1)$ & $(0.88,0.88,0.88)$ & $(0.92,0.92,0.92)$ \\
\hline$A_{4}$ & $(0.65,0.85,1)$ & $(0.6,0.8,1)$ & $(0.45,0.65,0.85)$ & $(0.45,0.65,0.85)$ & $(0.75,0.95,1)$ & $(0.8,1,1)$ & $(1,1,1)$ & $(1,1,1)$ \\
\hline$A_{5}$ & $(0.43,0.63,0.78)$ & $(0.65,0.85,1)$ & $(0.7,0.9,1)$ & $(0.43,0.63,0.78)$ & $(0.45,0.65,0.85)$ & $(0.6,0.8,1)$ & $(0.98,0.98,0.98)$ & $(1,1,1)$ \\
\hline
\end{tabular}

Table 7. The weighted normalized fuzzy decision matrix.

\begin{tabular}{|c|c|c|c|c|c|c|c|c|}
\hline \multicolumn{9}{|c|}{ Criteria } \\
\hline & $C_{1}$ & $C_{2}$ & $C_{3}$ & $C_{4}$ & $C_{5}$ & $C_{6}$ & $C_{7}$ & $C_{8}$ \\
\hline$A_{1}$ & $(0.10,0.28,0.60)$ & $(0.11,0.31,0.60)$ & $(0.46,0.84,1)$ & $(0.19,0.35,0.6)$ & $(0.23,0.49,0.78)$ & $(0.18,0.41,0.74)$ & $(0.36,0.55,0.59)$ & $(0.29,0.42,0.45)$ \\
\hline$A_{2}$ & $(0.13,0.33,0.67)$ & $(0.11,0.28,0.55)$ & $(0.41,0.77,0.93)$ & $(0.33,0.62,1)$ & $(0.23,0.49,0.78)$ & $(0.21,0.41,0.69)$ & $(0.30,0.45,0.48)$ & $(0.63,0.90,0.97)$ \\
\hline$A_{3}$ & $(0.16,0.38,0.74)$ & $(0.31,0.62,0.95)$ & $(0.42,0.79,1)$ & $(0.21,0.45,0.78)$ & $(0.23,0.49,0.78)$ & $(0.28,0.55,0.95)$ & $(0.51,0.77,0.84)$ & $(0.60,0.86,0.92)$ \\
\hline$A_{4}$ & $(0.28,0.55,0.95)$ & $(0.29,0.58,0.95)$ & $(0.29,0.60,0.85)$ & $(0.25,0.51,0.85)$ & $(0.45,0.81,1)$ & $(0.34,0.65,0.95)$ & $(0.58,0.88,0.95)$ & $(0.65,0.93,1)$ \\
\hline$A_{5}$ & $(0.18,0.41,0.74)$ & $(0.31,0.62,0.95)$ & $(0.46,0.84,1)$ & $(0.24,0.49,0.78)$ & $(0.27,0.55,0.85)$ & $(0.26,0.52,0.95)$ & $(0.57,0.86,0.93)$ & $(0.65,0.93,1)$ \\
\hline
\end{tabular}

superiority over each other, and $A_{5}$ has no superiority over any alternative. Relation (27) indicates the relationships between the alternatives, while $X \succ Y$

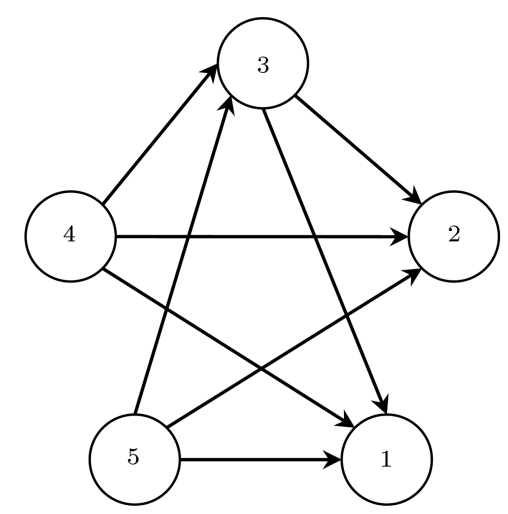

Figure 5. The corresponding graph of matrix $F$. means that $X$ is superior over $Y$ :

$$
\left\{A_{5}, A_{4}\right\} \phi A_{3} \phi\left\{A_{1}, A_{2}\right\} .
$$

To survey the proposed approach of this study, this problem is also solved by fuzzy TOPSIS and the results are presented in Table 15 . On the basis of the fuzzy TOPSIS method, $A_{4}$ is preferred to $A_{5}, A_{5}$ is preferred to $A_{3}, A_{3}$ is preferred to $A_{1}$, and $A_{1}$ is preferred to $A_{2}$ $\left(A_{4} \phi A_{5} \phi A_{3} \phi A_{1} \phi A_{2}\right)$, while, on the basis of the fuzzy ELECTRE method and judgment of the members of technical committee, $A_{5}$ is preferred to $A_{4}$ and other alternatives; therefore, $A_{5}$ has been selected as the best alternative.

The ELECTRE-based approach results, due to the consideration of different states of superiority, indifference, and incomparability between the alternatives, 
are apparently better than the TOPSIS-based (or other similar ranking methods) approach in which only the simple ranking of the alternatives is considered, especially when the number of the alternatives is greater.

Table 8. The concordance sets.

\begin{tabular}{cc}
\hline$\left(\boldsymbol{S}_{\boldsymbol{L K}}\right)$ & Concordanced sets \\
\hline$S_{12}$ & $\{2,3,5,7\}$ \\
$S_{13}$ & $\{3,5\}$ \\
$S_{14}$ & $\{-\}$ \\
$S_{15}$ & $\{3\}$ \\
$S_{21}$ & $\{4,5,8\}$ \\
$S_{23}$ & $\{3,4\}$ \\
$S_{24}$ & $\{4\}$ \\
$S_{25}$ & $\{1,2,4,5,6,7,8\}$ \\
$S_{31}$ & $\{1,2,3,5,6,7\}$ \\
$S_{32}$ & $\{2,3\}$ \\
$S_{34}$ & $\{1,2,4,5\}$ \\
$S_{35}$ & $\{1,2,5,6,7,8\}$ \\
$S_{41}$ & $\{1,4,5,6,7,8\}$ \\
$S_{42}$ & $\{1,4,5,6,7,8\}$ \\
$S_{43}$ & $\{1,2,3,4,5,6,7,8\}$ \\
$S_{45}$ & $\{1,2,3,5,6,7,8\}$ \\
$S_{51}$ & $\{1,2,3,4,5,7,8\}$ \\
$S_{52}$ & $\{2,3,8\}$ \\
$S_{53}$ &
\end{tabular}

Table 9. The non-concordance sets.

\begin{tabular}{cc}
\hline$\left(\boldsymbol{D}_{\boldsymbol{L K}}\right)$ & Non-concordanced sets \\
\hline$D_{12}$ & $\{1,4,5,6,8\}$ \\
$D_{13}$ & $\{1,2,4,5,6,7,8\}$ \\
$D_{14}$ & $\{1,2,4,5,6,7,8\}, 5,6,7,8\}$ \\
$D_{15}$ & $\{2,3,5,7\}$ \\
$D_{21}$ & $\{1,2,3,5,6,7\}$ \\
$D_{23}$ & $\{1,2,5,6,7,8\}$ \\
$D_{24}$ & $\{1,2,3,5,6,7,8\}$ \\
$D_{25}$ & $\{3,5\}$ \\
$D_{31}$ & $\{4,5,8\}$ \\
$D_{32}$ & $\{1,4,5,6,7,8\}$ \\
$D_{34}$ & $\{1,2,3,4,5,7,8\}$ \\
$D_{35}$ & $\{3\}$ \\
$D_{41}$ & $\{3\} 4\}$ \\
$D_{42}$ & $\{2,3,8\}$ \\
$D_{43}$ & $\{3\}$ \\
$D_{45}$ & $\{4\}$ \\
$D_{51}$ & $\{2,6\}$ \\
$D_{52}$ & $\{1,4,5,6,7,8\}$ \\
$D_{53}$ & \\
$D_{54}$ &
\end{tabular}

\section{Conclusion}

Due to the importance of the personnel selection problem and its significant role in any organization and also with regard to its multi-dimensionality, in this

Table 11. The non-concordance matrix.

\begin{tabular}{cccccc}
\hline & \multicolumn{5}{c}{ Alternatives } \\
\cline { 2 - 6 } Alternatives & $\boldsymbol{A}_{\mathbf{1}}$ & $\boldsymbol{A}_{\mathbf{2}}$ & $\boldsymbol{A}_{\mathbf{3}}$ & $\boldsymbol{A}_{\mathbf{4}}$ & $\boldsymbol{A}_{\mathbf{5}}$ \\
\hline$A_{1}$ & - & 1 & 1 & 1 & 1 \\
$A_{2}$ & 1 & - & 1 & 1 & 1 \\
$A_{3}$ & 0.13 & 0.54 & - & 1 & 1 \\
$A_{4}$ & 0.40 & 0.32 & 0.62 & - & 0.94 \\
$A_{5}$ & 0 & 0.41 & 0.26 & 1 & - \\
\hline
\end{tabular}

Table 12. The effective concordance matrix of $H$.

\begin{tabular}{cccccc}
\hline & \multicolumn{5}{c}{ Alternatives } \\
\cline { 2 - 6 } Alternatives & $\boldsymbol{A}_{\mathbf{1}}$ & $\boldsymbol{A}_{\mathbf{2}}$ & $\boldsymbol{A}_{\mathbf{3}}$ & $\boldsymbol{A}_{\mathbf{4}}$ & $\boldsymbol{A}_{\mathbf{5}}$ \\
\hline$A_{1}$ & - & 0 & 0 & 0 & 0 \\
$A_{2}$ & 0 & - & 0 & 0 & 0 \\
$A_{3}$ & 1 & 1 & - & 0 & 0 \\
$A_{4}$ & 1 & 1 & 1 & - & 1 \\
$A_{5}$ & 1 & 1 & 1 & 0 & - \\
\hline
\end{tabular}

Table 13. The effective non-concordance matrix of $G$.

\begin{tabular}{cccccc}
\hline & \multicolumn{5}{c}{ Alternatives } \\
\cline { 2 - 6 } Alternatives & $\boldsymbol{A}_{\mathbf{1}}$ & $\boldsymbol{A}_{\mathbf{2}}$ & $\boldsymbol{A}_{\mathbf{3}}$ & $\boldsymbol{A}_{\mathbf{4}}$ & $\boldsymbol{A}_{\mathbf{5}}$ \\
\hline$A_{1}$ & - & 0 & 0 & 0 & 0 \\
$A_{2}$ & 0 & - & 0 & 0 & 0 \\
$A_{3}$ & 1 & 1 & - & 0 & 0 \\
$A_{4}$ & 1 & 1 & 1 & - & 0 \\
$A_{5}$ & 1 & 1 & 1 & 0 & - \\
\hline
\end{tabular}

Table 14. The total matrix of $F$.

\begin{tabular}{cccccc}
\hline & \multicolumn{5}{c}{ Alternatives } \\
\cline { 2 - 6 } Alternatives & $\boldsymbol{A}_{\mathbf{1}}$ & $\boldsymbol{A}_{\mathbf{2}}$ & $\boldsymbol{A}_{\mathbf{3}}$ & $\boldsymbol{A}_{\mathbf{4}}$ & $\boldsymbol{A}_{\mathbf{5}}$ \\
\hline$A_{1}$ & - & 0 & 0 & 0 & 0 \\
$A_{2}$ & 0 & - & 0 & 0 & 0 \\
$A_{3}$ & 1 & 1 & - & 0 & 0 \\
$A_{4}$ & 1 & 1 & 1 & - & 0 \\
$A_{5}$ & 1 & 1 & 1 & 0 & - \\
\hline
\end{tabular}

Table 10. The concordance matrix.

\begin{tabular}{cccccc}
\hline & \multicolumn{5}{c}{ Alternatives } \\
\cline { 2 - 6 } Alternatives & $\boldsymbol{A}_{\mathbf{1}}$ & $\boldsymbol{A}_{\mathbf{2}}$ & $\boldsymbol{A}_{\mathbf{3}}$ & $\boldsymbol{A}_{\mathbf{4}}$ & $\boldsymbol{A}_{\mathbf{5}}$ \\
\hline$A_{1}$ & - & $(2.31,3.39,3.9)$ & $(1.25,1.78,2)$ & $(0,0,0)$ & $(0.65,0.93,1)$ \\
$A_{2}$ & $(2.23,3.21,3.95)$ & - & $(1.8,2.56,3)$ & $(1.2,1.71,2)$ & $(0.55,0.78,1)$ \\
$A_{3}$ & $(3.72,5.47,6.8)$ & $(3.17,4.69,5.8)$ & - & $(1.13,1.66,1.95)$ & $(0.91,1.38,1.9)$ \\
$A_{4}$ & $(3.29,4.82,5.85)$ & $(3.17,4.69,5.8)$ & $(3.24,4.74,5.85)$ & - & $(3.24,4.74,5.85)$ \\
$A_{5}$ & $(4.37,6.4,7.8)$ & $(3.82,5.62,6.8)$ & $(3.94,5.75,6.85)$ & $(1.78,2.59,2.95)$ & - \\
\hline
\end{tabular}


Table 15. The results of TOPSIS.

\begin{tabular}{ccccc}
\hline Alternatives & $\begin{array}{c}\text { Distance from the ideal } \\
\text { positive answer } \boldsymbol{d}^{+}\end{array}$ & $\begin{array}{c}\text { Distance from the ideal } \\
\text { negative answer } \boldsymbol{d}^{-}\end{array}$ & $\boldsymbol{R I}=\frac{\boldsymbol{d}^{-}}{\boldsymbol{d}^{-}+\boldsymbol{d}^{+}}$ & Ranking \\
\hline$A_{1}$ & 0.07 & 0.03 & 0.3 & 4 \\
$A_{2}$ & 0.08 & 0.02 & 0.2 & 5 \\
$A_{3}$ & 0.04 & 0.06 & 0.6 & 3 \\
$A_{4}$ & 0.02 & 0.08 & 0.8 & 1 \\
$A_{5}$ & 0.03 & 0.07 & 0.7 & 2 \\
\hline
\end{tabular}

paper, an MCDM model is presented for the personnel selection problem. To solve the problem, a fuzzy ELECTRE method is used. A critical advantage of this evaluation method is its capacity to point to the exact needs of a decision-maker and suggest an appropriate evaluation approach.

There are both qualitative and quantitative criteria in the model, while qualitative criteria are ranked by application of linguistic variables. At the end, by a numerical real example, the proposed method is illustrated and the results are compared with those of a similar, yet TOPSIS-based, method. Finally, it proves that the new ELECTRE-based approach is better, especially because the TOPSIS-based method only considers the simple ranking of the alternatives, but the ELECTRE one covers all the different states.

\section{References}

1. Zhang, Sh. and Liu, S. "A GRA-based intuitionistic fuzzy multi-criteria group decision making method for personnel selection", Expert Systems with Applications, 38(9), pp. 11401-11405 (2011).

2. Robertson, I.T. and Smith, M. "Personnel selection", Journal of Occupational and Organizational Psychology, 74(4), pp. 441-472 (2001).

3. Hooper, R.S., Galvin, T.P., Kilmer, R.A., and Liebowitz, J. "Use of an expert system in a personnel selection process", Expert Systems with Applications, 14(4), pp. 425-432 (1998).

4. Mehrabad, M.S. and Brojeny, M.F. "The development of an expert system for effective selection and appointment of the jobs applicants in human resource management", Journal of Computers \& Industrial Engineering, 53(2), pp. 306-312 (2007).

5. Shih, H.S., Huang, L.C., and Shyur, H.J. "Recruitment and selection processes through an effective GDSS", Journal of Computers and Mathematics with Applications, 50(10-12), pp. 1543-1558 (2005).

6. Chien, C.F. and Chen, L.F. "Data mining to improve personnel selection and enhance human capital: A case study in high-technology industry", Journal of Expert Systems with Applications, 34, pp. 280-290 (2008).

7. Dagdeviren, M. "A hybrid multi-criteria decisionmaking model for personnel selection in manufacturing systems", Journal of Intelligent Manufacturing, 21(4), pp. 451-460 (2010).

8. Jereb, E., Rajkovic, U., and Rajkovic, V. "A hierarchical multi-attribute system approach to personnel selection", International Journal of Selection and Assessment, 13(3), pp. 198-205 (2005).

9. Capaldo, G. and Zollo, G. "Applying fuzzy logic to personnel assessment: a case study", Omega, the International Journal of Management Science, 29(6), pp. 585-597 (2001).

10. Miller, G. and Feinzing S. "Fuzzy sets and personnel selection: discussion and application", Journal of Occupational and Organizational Psychology, 66(2), pp. 163-169 (1993).

11. Akdag, H., Kalayc, T., Karagöz S., Zülfikar, H., and Giz, D. "The evaluation of hospital service quality by fuzzy MCDM", Applied Soft Computing, 23, pp. 239248 (2014).

12. Liang, G.S. and Wang, M.J. "Personnel selection using fuzzy MCDM algorithm", European Journal of Operational Research, 78(1), pp. 22-33 (1994).

13. Karsak, EE. "Personnel selection using a fuzzy MCDM approach based on ideal and anti-ideal solutions", Lecture Notes in Economics and Mathematical Systems, 507, pp. 393-402 (2001).

14. Dursun, M. and Karsak, E.E. "A fuzzy MCDM approach for personnel selection", Expert Systems with Applications, 37(6), pp. 4324-4330 (2010).

15. Kabak, M., Burmaog, S., and Kazançoglu, Y. "A fuzzy hybrid MCDM approach for professional selection", Expert Systems with Applications, 39(3), pp. 35163525 (2012).

16. Sanga, X., Liu, X., and Qin, J. "An analytical solution to fuzzy TOPSIS and its application in personnel selection for knowledge-intensive enterprise", Applied Soft Computing, 30, pp. 190-204 (2015).

17. Kelemenis, A. and Askounis, D. "A new TOPSISbased multi-criteria approach to personnel selection", Expert Systems with Applications, 37(7), pp. 49995008 (2010).

18. Güngör, Z., Serhadlıoglu, G., and Kesen, S.E. "A fuzzy AHP approach to personnel selection problem", Journal of Applied Soft Computing, 9(2), pp. 641-646 (2009). 
19. Lin, H.T. "Personnel selection using analytic network process and fuzzy data envelopment analysis approaches", Journal of Computers \& Industrial Engineering, 59(4), pp. 937-944 (2010).

20. Afshari, A.R., Yusuff, R.M., and Derayatifar, A.R. "Linguistic extension of fuzzy integral for group personnel selection problem", Arabian Journal for Science and Engineering, 38(10), pp. 2901-2910 (2013).

21. Alguliyev, R.M., Aliguliyev, R.M., and Mahmudova, R.S. "Multicriteria personnel selection by the modified fuzzy VIKOR method", Scientific World Journal, pp. 1-16 (2015).

22. Daneshvar, R.B. and Erol, S. "Selecting the best project using the fuzzy ELECTRE method method", Mathematical Problems in Engineering, pp. 1-12 (2012).

23. Kaufmann, A. and Gupta, M.M., Fuzzy Mathematical Models in Engineering and Management Science, Amsterdam: North-Holland (1988).

24. Karsak, EE. "Distance-based fuzzy MCDM approach for evaluating flexible manufacturing system alternatives", International Journal of Production Research, 40(13), pp. 3167-3181 (2002).

25. Cheng, CH. "A new approach for ranking fuzzy numbers by distance method", Journal of Fuzzy Sets and Systems, 95(3), pp. 307-317 (1998).

26. Roy, B. "Ranking and choice in the presence of multiple points of view (the method ELECTRE)" [Classement et choix en presence de points de vue multiples (la methode ELECTRE)], RAIRO - Operations Research - Recherche Opérationnelle, 2, pp. 57-75 (1968).

27. Kangas, A., Kangas, J., and Pykäläinen, J. "Outranking methods as tools in strategic natural resources planning", Silva Fennica, 35(2), pp. 215-227 (2001).
28. Rogers, M., Bruen, M., and Maystre, L.Y. Electre and Decision Support, Methods and Applications in Engineering and Infrastructure Investment, Boston: Kluwer Academic (1999).

29. Montazer, G.A., Qahri Saremi, H., and Ramezani, M. "Design a new mixed expert decision aiding system using fuzzy ELECTRE III method for vendor selection", Journal of Expert Systems with Applications, 36(8), pp. 10837-10847 (2009).

30. Siler, W. and Buckley, J.J., Fuzzy Expert Systems and Fuzzy Reasoning, New Jersey, NJ: Wiley (2005).

\section{Biographies}

Milad Jasemi accomplished his BSc, MSc, and PhD in Industrial Engineering at Iran University of Science and Technology, Sharif University of Technology, and Amirkabir University of Technology, respectively, all in Tehran, Iran in 1999-2010. Currently, he is an Assistant Professor at K.N. Toosi University of Technology, and Azad University-Masjed Soleyman branch. His research interests are financial engineering, risk management, and multiple-criteria decision making. Moreover, he has been at Wayne State University, MI, USA as a visiting scholar (Post-Doc fellow) for the last year.

Elham Ahmadi accomplished both her BSc and MSc in Industrial Engineering at Yazd University, Yazd, Iran in 2007-2013. Currently, he is a Manager in Human Resource section of a successful Engineering Company in Isfahan, Iran. Her research interests are systems and methods optimization. 